The Geneva Papers on Risk and Insurance, 14 (No. 52, July 1989), 275-278

\title{
Comment : \\ «The Application of the Continuous-Time Theory of Finance to swap Valuation»
}

\author{
by Bruno Solnik*
}

Professor Robert Merton has been the pioneer of the modern time-continuous approach to finance. This approach has been a revolution in the area of financial analysis and widely used by financial decision makers throughout the world. His contribution in terms of financial understanding of the working of financial markets and institutions is equally important as illustrated by today's presentation. In my brief comment, I would like to emphasize why the continuous-time theory of finance has so much practical relevance to international finance, my field of specialty. I would also like to touch on an issue that Robert Merton did not have time to detail in his presentation, namely credit risk to illustrate his point that the modern theory of finance provides a framework to analyze, price and manage credit risk exposure.

The multi-currency environment adds another dimension and complexity to finance. For example, a French and American insurance company would not measure the return and risk on their portfolio of assets using the same numeraire. ${ }^{1}$ Because of real exchange rate movements, the real return on the same asset, say a share of IBM, will be viewed as different by the two investors. In terms of valuation, the French investor multiplies the dollar price of IBM by the franc/dollar exchange rate. In order to price assets in an international framework, we have to be able to handle analytically the product of two random prices (IBM and the exchange rate). The continuous-time approach allows us to do that. Robert Merton's paper is sufficiently rich in equations and references so that I do not need to add my own technical contribution. Let me just illustrate in my comment how the continuoustime approach and the Contingent-Claims Analysis (CCA) described by Robert Merton is of great practical importance in international finance.

* Professor of Finance, Centre HEC-ISA, 78350 Jouy-en-Josas, France.

${ }^{1}$ I do not wish to address here the question of the numeraire that should be used and will assume that the domestic currency is used to value an asset and its return. For a review of international asset pricing and a discussion of this point see Adler and Dumas (1983). 


\section{Swaps and international financial intermediation}

In the past few years, the trend towards global, international finance has rapidly accelerated. Investments and financing cut across markets and currencies. A financial institution (bank or insurance company) or a corporation has liabilities and assets denominated in numerous currencies. Because it cannot (nor wishes to) exactly match every liability with an asset in the same currency for the same amount and date, it is exposed to the volatility of currency markets. This has lead to the development of multi-currency instruments such as bonds, swaps and various types of options as well as sophisticated techniques of currency risk management.

Swaps have been a recent development in the world of finance. Morgan Stanley estimated that the total volume of swaps outstanding at the start of 1988 was around 300 billion dollars. These swaps are used to manage interest rate or currency risk. They have partly developed by taking advantage of pricing differences across national bond markets. To get back to Robert Merton's presentation, the swap market is a good illustration of his theory of innovation in financial intermediation. Ten years ago, when the swap market started to develop, there is no doubt that transaction costs where high to package such a product, that the various markets were quite segmented especially geographically and that information was still poor. Ten years ago, a financial institution could price a swap far away from a theoretical, efficient-market derived, CCA valuation. By selling swaps, such financial institutions were providing a real service to the international financial community. This role was initially devoted to big commercial banks with an extensive international network able to access information and transactions in various local markets. Nowadays the market for currency and interest rate swap has dramatically grown. The geo-political advantage has progressively disappeared and all kinds of intermediaries are offering swaps at conditions that reflect very small transaction costs.

Because swaps are private deals and appear as off-balance sheet items, they are usually not priced in the balance sheet of the swap contractor (the "swapor"). Still, it is extremely important for a swapor or a bank granting other types of credit to a swapor to asses the market value of its outstanding swaps. However these instruments are often not traded on a secondary market so there is no official market price; furthermore a theoretical value for these instruments is not trivial to determine since they involve movements in two interest rates and a foreign exchange rate. However institutions engaged in active multi-currency management of their assets/debt structure often carry several hundred swaps in their books. ${ }^{2}$ The whole financial system has become sensitive to the issue of swap pricing and the possible impact of default risk. An important question has arisen: how de we price swaps, taking into account the default risk on such complex instruments? And therefore how does a bank determines the default markup that it should charge to a swapor to be appropriately compensated for default risk?

\section{The pricing of swaps}

A swap is a contract to exchange the net balance of two cash flows linked to interest rates and exchange rates. When the two cash flows are in the same currency but one of them

\footnotetext{
${ }^{2}$ For example the Gaz be France is reported to have several hundred swaps outstanding with various parties (see Risk, December 1987).
} 
is fixed while the other is indexed on a short term interest rate, it is usually called an interest rate swap. When the two cash flows are fixed, but denominated in two different currencies, it is usually called a currency swap.

Deriving the fair value of a default-free swap is fairly straightforward. The value of the swap will go up or down depending on the movements in interest rates and exchange rate after the day of contracting, but the swap can be seen as a package of two default-free bond. For example, an interest rate swap can be priced as the difference between a floating rate bond and a fixed coupon bond. A currency swap can be priced as the difference between two fixed coupon bonds denominated in different currencies. However, the problem becomes more complex when one of the swapor carries default risk.

This can be resolved in the CCA continuous-time framework introduced by Robert Merton. Let's consider a simple interest rate swap written in a single currency, ${ }^{3}$ whereby the bank agrees to pay $C$, a fixed coupon set at the ongoing yield for a riskless borrower and receives $i(t)+m$, a variable coupon paid by "the swapor"; this coupon is equal to the riskless short term interest rate at time $t$ of each swap payment plus a markup $m$ to reflect the default risk of the swapor. Assume that we know the credit risk spread $\mu$ that the client (swapor) has to pay on a straight loan contract. Why should the markup $m$ on charged on a swap be different from the spread $\mu$ over the riskfree rate charged on a straight loan?

At each swap date $t$, the cash flow to the bank will depend on market conditions and the fact that the swapor has, or not, defaulted. If the swapor does not default, the bank will get (pay if negative):

$$
i(t)+m-C
$$

If the swapor defaults, the bank still has to honor its debt if the cash flow is negative, but will not receive it if the cash flow is positive:

$$
\text { Cash flow }=\min \{0, i(t)+m-C\})=-\max \{0, C-m-i(t)\}
$$

If we assess a probability of default $p$, the overall expected cash flow is:

$$
(1-p) E[i(t)+m-C]-p E[\max \{0, C-m-i(t)\}]
$$

Consider a simple one-year swap for illustration purposes. Assume that this default risk can be diversified away across clients and that the expected future interest rate $i(t)$ is equal to the current rate $C$ (pure expectation theory). The default markup should be set at time of issue so that the swap has a fair price of zero for the two parties:

$$
1 /(1+C)\{(1-p) E[i(t)+m-C]-p E[\max \{0, C-m-i(t)\}]\}=0
$$

hence:

$$
m(1-p) /(1+C)-p \text { FLOOR }(i(t), C-m, 1)=0
$$

where the second term in the equation is the price of a floor ${ }^{4}$ an interest rate option commonly written by banks and that can be valued looking at market quotations. This equation

\footnotetext{
${ }^{3}$ The case of a currency swap is slightly more complex, but can be analyzed in the same manner.

${ }^{4} \mathrm{~A}$ floor is a contract where the seller agrees to pay the difference between a present interest rate (the exercise price) and the market interest rate if this difference is positive, A Cap is the reverse option (if the market interest rate is above the prespecified interest rate).
} 
allows to determine the terms to be set on the (default) risky swap given 1) the value of a one-year defaultfree bond, 2) the value of a defaultfree option on the interest rate and 3) the probability of default. A similar equation obtains for a swap with a longer maturity and involve many more defaultfree securities but whose prices can be observed in, or derived from, the market place. The interesting result is that we can derive the value of the swap from parameters observed in the market plus an assessment of the probability of default. Actually this probability $p$ can be inferred from the price of a bond issued by that same swapor if the swapor is at the same time using straight borrowing. ${ }^{5}$

The assumption of default risk diversifiability implies that the expected return on lending to this client is equal to the current riskfree interest rate $C$ :

$$
1=\{p(0)+(1-p)(1+C+\mu)\} /(1+C)
$$

hence, the yield spread $\mu$ :

$$
\mu=(p / 1-p)(1+C)
$$

Replacing in equation (1), we get the relation:

$$
m=\mu . F L O O R(i(t), C-m, 1)
$$

Note that the relation is independent of the probability of default in this simple case.

here is a numerical application:

$p=0.05$

$c=0.10$

$F L O O R=0.02$ (set arbitrarily at a reasonable level although it is a function of $\mu$ )

hence

$$
\begin{aligned}
& \mu=(.05 / .95) 1.10=0.0579=5.79 \% \text { or } 579 \text { basis points } \\
& m=0.0579) 0.02=.0012=12 \text { basis points }
\end{aligned}
$$

A similar result could be derived for currency swaps, where the value of an interest rate option would be replaced by the value of a currency option.

${ }^{5}$ By looking at the spread $\mu$ between the rate paid by this risky swapor and the market riskless rate. We assume that the lendor looses all capital and interest in case of default. 